\title{
A survey of clinical nurses' research needs for research support from university faculty
}

\author{
Akiko Hiyama*1, Mizue Fujii ${ }^{1}$, Hiromi Kikuchi ${ }^{1}$, Masumi Muramatsu ${ }^{1}$, Natsuyo Ono ${ }^{1}$, Chiyoko Inomata ${ }^{1}$, Katsunori \\ Yamamoto ${ }^{2}$ \\ ${ }^{1}$ School of Nursing, Sapporo City University, Japan \\ ${ }^{2}$ School of Nursing, Tenshi Collage, Japan
}

Received: September 21, 2019

Accepted: October 31, 2019

Online Published: November 11, 2019

DOI: $10.5430 /$ jnep.v10n2p62

URL: https://doi.org/10.5430/jnep.v10n2p62

\begin{abstract}
Supporting university faculty who are engaging in clinical research through continuing education can increase the effectiveness of education. This descriptive study aimed to describe the needs of nurses who are pursuing research and to clarify future activities to support their research. Data were collected using a questionnaire. Participants included 249 nurses currently working at seven different hospitals and who had conducted research supported by a university from FY2007 to FY2016. The questionnaire assessed the degree of difficulty of pursuing research and the need for support. In total, 177 nurses were included in the final analysis (valid response rate: $65.8 \%$ ). The ethics review question had a median score of 3 , indicating moderate difficulty. Both the methods and data analysis questions had median scores of 5 on the support need scale, indicating a high need for support, whereas the presentation question had a median score of 3 (moderate need for support). The literature review had the lowest percentage of participants who reported being satisfied with the support received, at $83.1 \%$; however, $98.1 \%$ were satisfied with the support received for the ethics review. These results indicate that the following factors should be addressed to better support research among clinical nurses: teaching methods, reviewing the literature, selecting an appropriate research method, and analyzing the data. Our results also demonstrated that nurses were relatively dissatisfied with the methods of communication used in research. Nurses reported that future support should emphasize improving methods of support and effectively clarifying the needs of human resource development.
\end{abstract}

Key Words: Support system of research, Nursing research, Continuing education

\section{INTRODUCTION}

Research activities conducted by clinical nurses are an important aspect of their continuing education. Nurses are expected to engage in continuous quality improvement through the practice of evidence-based nursing. Therefore, nurses must scientifically demonstrate their daily practice and verify the effects of high quality trial practices. However, they encounter numerous barriers for engaging in research, including time constraints, insufficient knowledge of the current literature, lack of authority to change their practices, poor critical appraisal skills, and inadequate support for the implementation of research findings. ${ }^{[1]}$

To address these issues in nursing research, Sapporo City University has been continually supporting nursing research since 2007. Specifically, university faculty now provides direct support for nursing research occurring in multiple area hospitals. Previous research has demonstrated that university faculty supports and evaluates clinical research using lecture-based knowledge provision and group work. ${ }^{[2]}$ How-

*Correspondence: Akiko Hiyama; Email: a.hiyama@ scu.ac.jp; Address: School of Nursing, Sapporo City University, Japan. 
ever, to date, no study has evaluated the benefits of providing continuous support over several years to nurses engaging in clinical research. The university involved in the present study has been working on pioneering projects for 10 years. Such collaboration between universities and hospitals has valuable benefits. First, these collaborations improve the quality of nursing care as research findings give meaning and relevance to nursing practice. Second, collaboration builds a foundation for enhancing the quality of basic education by strengthening communication between universities and hospitals, which provides practical and real-world educational opportunities for students. Lastly, these interactions emphasize the importance of teaching ability and nursing education as a practical science and increase the number of situations where university faculty have the opportunity to experience clinical practice. Therefore, universities that provide support for nursing research along with opportunities for group education contribute to improvements in quality of care and increase continuing education, such as nursing process, physical assessment, and educational training support. Nursing research support from Sapporo City University includes providing training on basic nursing research, education on research design, and presentations during group education. In addition, individual research groups have provided further support to clinical nurses by providing individualized guidance on the process of research planning to manuscript submission. These efforts are ongoing, and we continue to seek cooperation between universities and hospitals. The faculty now oversees individual research groups in the university, engages in discussion and provides support via email, and comments on individual research groups during research meetings. As part of the education to improve the practical skills of clinical nurses, research support is being provided by university faculty based on the hospitals' request. However, there are some problems with the research collaboration between hospitals and universities.

Previous research has shown that faculty who provide support to nurses in a manner that aligns with their research knowledge and their degree of understanding of the research motivated nurses to complete a given program. ${ }^{[2]}$ Miyashiba et al. ${ }^{[3]}$ investigated the research support provided to hospitals by universities for nursing managers and nurses in charge of research promotion projects. The authors found that few nurses were taught the knowledge and techniques necessary for conducting research $(22.5 \%)$, environmental adjustment and guidance (14.7\%), and the necessity of literature review and collaboration $(14.7 \%)$. These findings demonstrate a lack of research support by universities. Thus, while research exists on the problems experienced by nurses and nurse managers in charge of continuing education who

Published by Sciedu Press are conducting research projects, nurses' specific needs from research support have not yet been studied. Therefore, the aims of this study were (1) to clarify the difficulties faced by nurses and their support needs from the faculty, and (2) to describe the specific needs of nurses across the stages of the research process.

\section{METHOD}

\subsection{Study design}

This was a descriptive survey study. Since no research has been previously conducted to examine the needed research support for clinical nurses who continued to engage in research, a descriptive study design was selected in as being appropriate for this initial study on this topic.

\subsection{Participants}

Hospital departments and the nurses who supported them were identified from records. We asked the hospitals to identify those nurses who received research support from a university from FY2007 to FY2016. Through this process, the 249 nurses who received research support and were still working at the hospitals were identified.

\subsection{Data collection}

Drawing on past literature, ${ }^{[3-5]}$ we created a questionnaire for evaluating the difficulties faced by nurses and their support needs. Since the needs for research support differed depending on the stage of the research process, ${ }^{[3]}$ the research process was divided into 10 steps, which included the literature review, deciding on a research question, deciding on the methods to use, ethics review, data collection, data analysis, discussion, manuscript writing, presentation, and manuscript submission. To examine the areas for future support, questions were developed that assessed the perceived difficulty of each process and the need for support. In addition, we attempted to understand the current levels of support and the future areas of support needed from the university by asking about the level of support actually received in each process and the level of satisfaction with the support that was received. For each area, participants rated the degree of difficulty and the need for support. Each was rated on a five-point scale $(1=$ none, 2 = low, $3=$ moderate, $4=$ high, and $5=$ very high), where 1 indicated little difficulty/need for support and 5 indicated great difficulty/need for support.

We also evaluated the level of support and satisfaction with the support along the research process. We used seven questions to evaluate support received from the university, including support throughout the entire research process, assistance with motivation, training to conduct follow-ups, evaluating research activities, review of presentations and the 
manuscript, suggestions on how to utilize the study results in a clinical setting, and providing advice on direction according to individual research abilities. The questions concerning future research support provided by universities were developed by interviewing nursing administrators and educators in hospitals that were currently receiving support from universities. These questions were evaluated using a binary response scale.

Finally, we asked participants to provide their opinions on research support from the university using an open-response question. The entire questionnaire was anonymous. After reviewing the questionnaire by all authors and co-investigators, the questionnaire was validated following a review and confirmation by nursing support managers and educators at the hospital who were in charge of research support from the university. In addition, the questionnaire was piloted with 10 nurses who were study participants to ensure the clarity and difficulty of each item, the ease of answering items, and the number of items as having superficial validity.

\subsection{Survey procedure}

Written information about this study was sent to the nurse managers of the selected hospitals, who distributed the questionnaires to their nurses. Participants were asked to return their questionnaires within 2 weeks of receiving them. The completed questionnaires were deposited in collection boxes installed at each study institution. The survey period was from May 9 to June 30, 2017. As the questionnaire was completed anonymously, it was clearly stated in the written request to the participating nurses that the questionnaires could not be withdrawn after being submitted to the collection boxes.

\subsection{Data analysis}

The data were analyzed using IBM SPSS Statistics 23 for Windows (IBM Corp., Armonk, NY). Descriptive statistics were calculated for all the items, including frequencies, means, standard deviations, and medians. To analyze the open-ended questions, we coded in the smallest unit of semantic content, classified based on the similarity and dissimilarity of meaning, and given a name that reflected their meaning in the classification. This descriptive content was analyzed using the method of content analysis by Berelson. ${ }^{[6]}$

\subsection{Ethical considerations}

The study was conducted after approval has been obtained from the Ethical Committee of Sapporo City University (No. 1649-1). All potential participants received a general letter of introduction that included instructions for acceptance or refusal of participation. They were assumed to have given consent if the survey questionnaire was completed and posted to the research team. As noted above, all questionnaires were anonymous.

\section{RESULTS}

In total, 177 nurses completed the survey and were included in the final analysis (valid response rate: $65.8 \%$ ). When more than $50 \%$ of a questionnaire was incomplete, we determined that the data was invalid, but there was no corresponding answer sheet. Since each item was an independent question, even incomplete answers on the questionnaire were determined to be valid answers. We have reported the number of responses for each question. Participants had a mean of 14.9 years $(\mathrm{SD}=8.2)$ of work experience and had completed a mean of 4.9 research projects $(S D=4.5)$. Half the respondents $(n=90,50.8 \%)$ were staff nurses, followed by sub-managers $(n=38,21.5 \%)$, managers $(n=42,23.7 \%)$, and others $(n=7,3.4 \%)$.

\subsection{Difficulty and the need for support of each research process}

The median degree of difficulty was in the range of 4-5 across the 10 processes. The median need for support ranged from 3-5. The ethics review question had a median score of 3 on the difficulty rating, indicating intermediate difficulty (see Table 1). The methods and data analysis questions both had median scores of 5 on the support need rating, indicating a high degree of support needed. Presentation, on the other hand, had a median score of 3 on the support need rating (see Figures 1 and 2).

\subsection{Experience of and satisfaction with support}

A total of $86.3 \%$ respondents received support for determining the methods for their studies. However, few participants had received support for the presentation $(n=66)$ and submission of manuscripts $(n=57)$ because rather few nurses reached that far. As for their satisfaction with the support received, the area with the lowest percentage of satisfied participants was the literature review, at $83.1 \%$. By contrast, $98.1 \%$ of the participants were satisfied with the support received for their ethics review (see Table 2).

\subsection{Reasons that responders were satisfied with each re- search process}

\subsubsection{The literature review}

The reasons that responders were satisfied with the literature review included "I was recommended the appropriate document." "I obtained advice on retrieving documents appropriate for my purposes." As for why they were not satisfied with the literature review, participants said, "When it was necessary, I was not able to get advice" and "It was hard to be too high-level, and to follow it." 
Table 1. Degree of difficulty and support needed

\begin{tabular}{|c|c|c|c|c|c|c|c|c|}
\hline \multirow{2}{*}{$\begin{array}{l}\text { Research process } \\
\text { Literature review }\end{array}$} & \multicolumn{2}{|c|}{ Answer } & \multirow{2}{*}{$\begin{array}{l}\text { Median } \\
4\end{array}$} & \multicolumn{5}{|c|}{ Interquartile range } \\
\hline & 176 & Degree of the difficulty & & ( & 3 & - & 4 & ) \\
\hline & 176 & Degree of support needed & 4 & ( & 3 & - & 5 & ) \\
\hline \multirow[t]{2}{*}{ Deciding on the research theme } & 176 & Degree of the difficulty & 4 & ( & 3 & - & 4 & ) \\
\hline & 176 & Degree of support needed & 4 & ( & 3 & - & 5 & ) \\
\hline \multirow[t]{2}{*}{ Deciding on the methods to use } & 176 & Degree of the difficulty & 4 & ( & 3 & - & 5 & ) \\
\hline & 177 & Degree of support needed & 5 & ( & 4 & - & 5 & ) \\
\hline \multirow[t]{2}{*}{ Ethics review } & 177 & Degree of the difficulty & 3 & ( & 2 & - & 4 & ) \\
\hline & 177 & Degree of support needed & 3 & ( & 2 & - & 4.5 & ) \\
\hline \multirow[t]{2}{*}{ Data collection } & 175 & Degree of the difficulty & 4 & ( & 3 & - & 5 & ) \\
\hline & 175 & Degree of support needed & 4 & ( & 3 & - & 5 & ) \\
\hline \multirow[t]{2}{*}{ Data analysis } & 174 & Degree of the difficulty & 5 & ( & 4 & - & 5 & ) \\
\hline & 174 & Degree of support needed & 5 & ( & 4 & - & 5 & ) \\
\hline \multirow[t]{2}{*}{ Discussion } & 172 & Degree of the difficulty & 4 & ( & 4 & - & 5 & ) \\
\hline & 170 & Degree of support needed & 4 & ( & 4 & - & 5 & ) \\
\hline \multirow[t]{2}{*}{ Manuscript writing } & 172 & Degree of the difficulty & 4 & ( & 4 & - & 5 & ) \\
\hline & 170 & Degree of support needed & 4 & ( & 4 & - & 5 & ) \\
\hline \multirow[t]{2}{*}{ Presentation } & 170 & Degree of the difficulty & 4 & ( & 3 & - & 5 & ) \\
\hline & 170 & Degree of support needed & 3 & ( & 2 & - & 5 & ) \\
\hline \multirow[t]{2}{*}{ Manuscript submission } & 144 & Degree of the difficulty & 4 & ( & 3 & - & 5 & ) \\
\hline & 142 & Degree of support needed & 4 & ( & 3 & - & 5 & ) \\
\hline
\end{tabular}

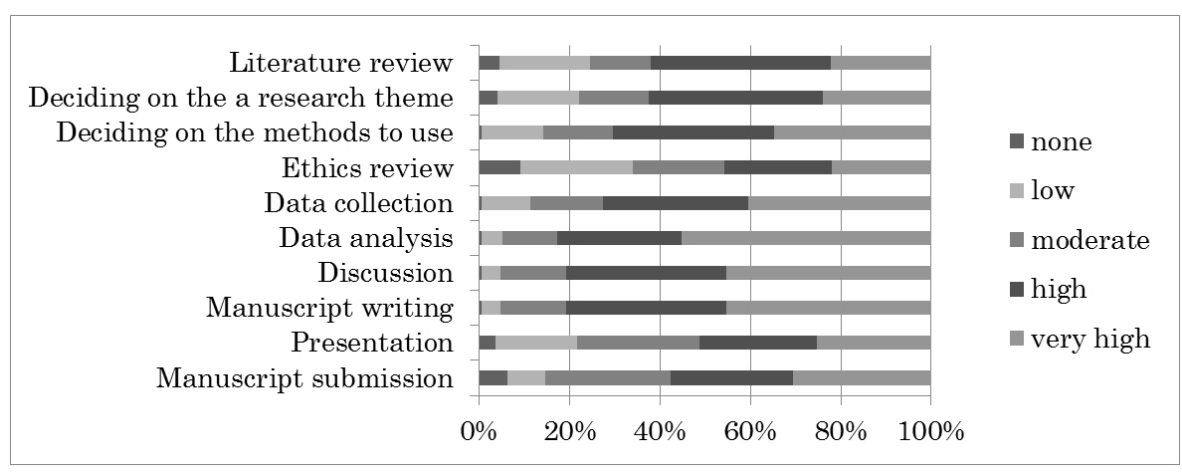

Figure 1. Degree of difficulty

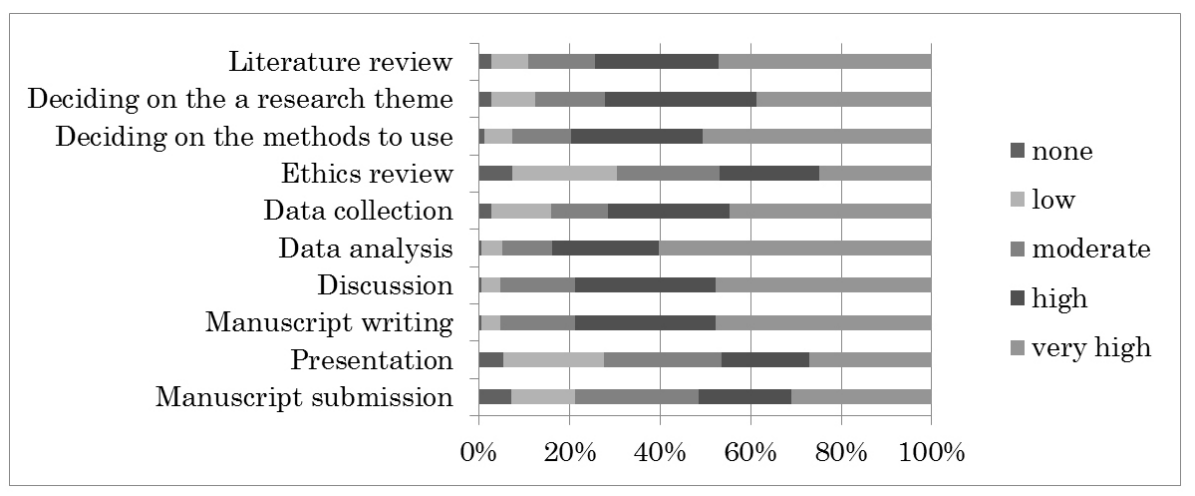

Figure 2. Degree of support needed 
Table 2. Experience of and satisfaction with support

\begin{tabular}{|c|c|c|c|c|c|c|}
\hline \multirow{2}{*}{ Research process } & \multirow{2}{*}{ Answer } & & \multicolumn{2}{|l|}{ Yes } & \multicolumn{2}{|l|}{ No } \\
\hline & & & Number & $\%$ & Number & $\%$ \\
\hline \multirow[t]{2}{*}{ Literature review } & 175 & Experience of support & 143 & 81.7 & 32 & 18.3 \\
\hline & 142 & Satisfaction with support & 118 & 83.1 & 24 & 16.9 \\
\hline \multirow[t]{2}{*}{ Deciding on the a research theme } & 173 & Experience of support & 138 & 79.8 & 35 & 20.2 \\
\hline & 135 & Satisfaction with support & 124 & 91.9 & 11 & 8.1 \\
\hline \multirow[t]{2}{*}{ Deciding on the methods to use } & 175 & Experience of support & 151 & 86.3 & 24 & 13.7 \\
\hline & 148 & Satisfaction with support & 136 & 91.3 & 13 & 8.7 \\
\hline \multirow[t]{2}{*}{ Ethics review } & 175 & Experience of support & 104 & 59.4 & 71 & 40.6 \\
\hline & 104 & Satisfaction with support & 102 & 98.1 & 2 & 1.9 \\
\hline \multirow[t]{2}{*}{ Data collection } & 174 & Experience of support & 125 & 71.8 & 49 & 28.2 \\
\hline & 120 & Satisfaction with support & 112 & 93.3 & 8 & 6.7 \\
\hline \multirow[t]{2}{*}{ Data analysis } & 173 & Experience of support & 135 & 78.0 & 38 & 21.9 \\
\hline & 129 & Satisfaction with support & 115 & 89.1 & 14 & 10.9 \\
\hline \multirow[t]{2}{*}{ Discussion } & 171 & Experience of support & 132 & 77.2 & 39 & 22.8 \\
\hline & 128 & Satisfaction with support & 116 & 90.6 & 12 & 9.4 \\
\hline \multirow[t]{2}{*}{ Manuscript writing } & 171 & Experience of support & 132 & 77.2 & 39 & 22.8 \\
\hline & 128 & Satisfaction with support & 116 & 90.6 & 12 & 9.4 \\
\hline \multirow[t]{2}{*}{ Presentation } & 170 & Experience of support & 66 & 38.8 & 104 & 61.2 \\
\hline & 65 & Satisfaction with support & 62 & 95.4 & 3 & 4.6 \\
\hline \multirow[t]{2}{*}{ Manuscript submission } & 145 & Experience of support & 57 & 39.3 & 88 & 60.7 \\
\hline & 56 & Satisfaction with support & 53 & 94.6 & 3 & 5.4 \\
\hline
\end{tabular}

\subsubsection{Deciding on a research theme}

The reasons that participants were satisfied with the support received for deciding on a research theme included "I was able to organize what I wanted to do, so I was able to decide on the theme" and "I was able to recognize again that my determined direction was not wrong." Conversely, they were dissatisfied with this support because "There was a difference of opinion on what to change with the university teacher" and "Previous support content was not continued."

\subsubsection{Methods to be used}

Participants were satisfied with the support received on deciding what methods to use for the following reasons: "I learned a method that I did not know" and "The accuracy improved." They were dissatisfied with this support because "The reply period was too long and contained little content" and "I could not understand [the methods] after only one lesson."

\subsubsection{Ethics review}

The reasons that participants were satisfied with the ethics review included "I learned to think more ethically" and "I got reference on the ethical viewpoints of subjects." Their reasons for being dissatisfied, however, included "The reply period was too long and contained little content" and "I could not understand [the ethics review process] after only one lesson."

\subsubsection{Data collection}

Participants were satisfied with the support obtained for data collection because "I was appropriately advised on how to collect data for my purposes" and "I my knowledge supplemented." They were dissatisfied because "[The support] was given an insufficient number of times" and "It was hard to follow because it was too high-level."

\subsubsection{Data analysis}

The reasons for being satisfied with support offered for their data analysis were "I received support many times" and "I was corrected when [the analysis] seemed to be outside of the theme." Their dissatisfaction was primarily due to "[The support] was given an insufficient number of times" and "It was hard to follow because it was too high-level."

\subsubsection{Discussion}

Participants tended to be satisfied with support to the discussion because "I was advised from various perspectives" and "The shortcomings were clearly pointed out." However, they were not satisfied because "I could not understand [what we were discussing] after only one lesson" and "It was hard to follow because it was too high-level." 


\subsubsection{Manuscript writing}

Participants were satisfied with the support provided for their manuscript writing because "I was given support repeatedly" and "I was able to organize the sentences to mix results, considerations, and conclusions." By contrast, they were dissatisfied because "I could not understand [the manuscript writing process] after only one lesson" and "The revision part was difficult to understand."

\subsubsection{Presentation}

The reasons that participants felt satisfied with support provided on presenting their research were "I learned a presentation method that made it easier for the listener to understand" and "I learned how to create a table." However, they cited "I was short of time and I could not receive enough support" and "The revision part was difficult to understand" as reasons that responders were not satisfied with the presentation.

\subsubsection{Manuscript submission}

Finally, participants cited "I was able to understand how to express myself in a limited number of characters" and "I could understand the points and correct them appropriately" as reasons to be satisfied with the support for their manuscript submission. However, they were dissatisfied with this support for the following reasons: "I wanted to give previous notice that the content required by peer review after submitting was difficult and "I could not get assistance until peer review."
3.4 Correlations between the number of studies experienced and difficulty and support needs of each area of the research process

We analyzed the correlations between the number of times that participants experienced a study and difficulty of each area of the research process. The correlation coefficients were as follows: literature review, $\mathrm{r}=-.21$; deciding on a research theme, $\mathrm{r}=-.24$; methods to be used, $\mathrm{r}=-.22$; ethics review, $\mathrm{r}=-.28$; data collection, $\mathrm{r}=-.22$; data analysis, $\mathrm{r}$ $=-.22$; and presentation, $\mathrm{r}=-.22$. We found negative weak correlations for all areas except for discussion, $r=-.02$; and manuscript writing, $r=-.02$. The relationship with no significant correlation was manuscript submission, $r=.06$.

There was a weak correlation between the number of times that participants experienced a study and the support needs of each area of the research process for only ethics review, $r=$ -.26. The very weak correlation coefficients were as follows: data analysis, $r=-.18$; discussion, $r=-.19$; manuscript writing; $r=-.19$; and presentation, $r=-.19$. Further, there were no significant correlations found for literature review, deciding on a research theme, methods to be used, data collection, manuscript submission.

\subsection{Necessity of research support by the university}

The 6 questions related to the need for research support from universities showed a high overall need. About $94.3 \%$ of respondents believed that assistance should be given by the university on training them to conduct follow-up studies, whereas only $79.0 \%$ believed that they required assistance with the motivation to do research (see Table 3 ).

Table 3. Necessity of research support by university faculty

\begin{tabular}{llllll}
\hline & \multirow{2}{*}{ Answer } & Yes & \multicolumn{2}{c}{ No } \\
\cline { 3 - 6 } & & Number & $\%$ & Number & \% \\
\hline Support through the entire process of research & 177 & 155 & 87.6 & 22 & 12.4 \\
Assistance with motivation & 176 & 139 & 79.0 & 37 & 21.0 \\
Training to conduct follow-up & 176 & 166 & 94.3 & 10 & 5.7 \\
Evaluating research activities & 176 & 157 & 89.2 & 19 & 10.8 \\
Review presentations and manuscript & 176 & 157 & 89.2 & 19 & 10.8 \\
Suggestion of the study that it could utilize in a clinic & 175 & 156 & 89.1 & 19 & 10.9 \\
\hline
\end{tabular}

\section{Discussion}

The purpose of this descriptive study was to describe the nurses' specific needs to proceed with the study and to clarify future activities that support the study. Data was collected using a questionnaire, and 177 nurses completed and analyzed the survey. As a result, the difficulty of the support received, the necessity of future support, positive and nega- tive opinions about support by faculty, and future needs for research support were revealed.

We found that the methods and data analysis had particularly high degrees of difficulty, and many respondents required support for data analysis. Furthermore, $10.9 \%$ of the nurses were dissatisfied with the support they received for data analysis. Miyashiba mentioned that many individuals had 
deficiencies in knowledge and techniques for data analysis, ${ }^{[3]}$ which inhibited the promotion of research. Therefore, the results of this study suggest that the technical difficulty of these two components of the research process may be one reason that participants largely felt that support from the university was necessary.

Conversely, participants had little difficulty with the ethics review and did not feel that they required more support for it compared to the other processes. Indeed, the largest percentage of satisfied participants was found for the ethics review question. In the survey that evaluated university research support, there was little support for ethical review. ${ }^{[4,7]}$ Therefore, nurses felt that they had received enough support for ethics review, probably because university faculty gave consideration for the research subjects and provided nurses with comprehensive information about ethical concerns in research. Although ethics review was rated as low in difficulty and did not receive much actual support, the fact that it is essential for the research process as a whole makes it worthy of support. This process should be continued because the difficulty and the level of satisfaction and the amount and quality of support were reported as being appropriate.

Compared to the other components of the research process, many respondents felt unsatisfied with the support received for reviewing the literature. Hutchinson and Johnston mentioned that one of the primary barriers to nursing research is a lack of awareness of the literature. ${ }^{[1]}$ In addition, this dissatisfaction may arise from the fact that supporting the literature review process is difficult for the faculty and could contribute to decreased motivation in nurses. The difficulty in this area is thought to be due to the understanding of the type of literature, the contractual coverage of the available literature search database, the method of collecting the literature to be collected, and the prolonged time required to review the literature. Faculty members were motivated to communicate the needs for completing a literature review, provide advice on search methods, and support the use of university libraries. However, the results of this study showed that the existing interventions in this area were insufficient for addressing the problems faced by clinical nurses. Therefore, identifying ways to reduce the difficulty by introducing support such as acquisition of higher motivation, reading of literature, and creation of review matrix is needed. Previous researchers have established goals, common objectives, mutual respect, willingness to negotiate and compromise, informed participation, information provision, and educators and clinicians and managers shared decision-making, to make partnerships. ${ }^{[8]}$ Through a formal research partnership mechanism, a separate focus was created for effort and used to move to tactical, operational, and interpersonal integration in this relationship.
Latimier and Kimbell also established a systematic curriculum and introduced a program for nurses to complete and submit scientific reviews and final qualitative assessments. ${ }^{[9]}$ This program was designed to educate nurses on the research process and enable them to lead research projects. According to these literature claims, nurses may become aware of the need for literature review by sharing goals between nurses and faculties, and by providing a systematic curriculum. In addition, it may be necessary to adjust the difficulty and develop a more systematic curriculum concerning research techniques in the future.

The results concerning the discussion indicate that there are problems in communication between nurses and university faculty. Nurses were largely dissatisfied with the frequency of contact with the university faculty, which they felt gave them insufficient support. In a research support program for nurses, Higashino et al. noted that most teaching took place through email exchanges. Given these issues, it is necessary to devise better ways of communicating - that is, that allow nurses and faculty to communicate more frequently and that do not rely on email. ${ }^{[2]}$ In addition, both parties should recognize that misunderstandings may occur if explanations are conducted primarily by email. Lee and Metcalf found that implementing clinical training in hospitals are effective for promoting research skills and resolving barriers to research (e.g., lack of time and poor research skills and knowledge). ${ }^{[10]}$ These results suggest that shortening the physical distance between nurses and university faculty might enable better communication.

Regarding future study support needs of clinical nurses, personnel training on the completion of research studies was highly necessary. Based on the results of the current levels of support, problems with communication between teachers and nurses have been clarified. Therefore, hospitals should consider requesting additional support to create a system that provides opportunities for additional advice to clinical nurses when needed. It will be difficult to promote clinical human resource development to support nursing research, given the limitations inherent in clinical settings (e.g., communication takes place primarily by email, difficulty in securing the necessary time). As mentioned in previous research, ${ }^{[11]}$ it is also necessary to identify the needs of research training leaders and to systematize support groups. A possible strategy for boosting clinical human resource development was hinted at by the correlational analysis between the number of studies completed and the difficulty of each component of the research process - the correlations were uniformly negative (save the discussion and manuscript writing components), indicating that the difficulty of each component decreases as individuals' research experience increases. As for the 
correlation between the number of studies experienced and support need ratings, only the ethics review question had a negative correlation, which suggests that even nurses with research experience may require support (other than for ethics review). Because research experience does not reduce the difficulty, appointing an experienced nurse as a leader in the hospital might not lead to an improvement in the quality of education. Therefore, personnel training should be further developed while expanding research support. In the future, hospital administrators and nurse managers need to grasp the readiness of nurses to receive research support as well as the ability to adjust the support method according to nurses' needs to efficiently utilize the limited resources of university faculty. These changes could contribute to improvements in the quality of research conducted by clinical nurses in hospitals.

A limitation of this study is that we investigated only the current states of the research support in multiple hospitals affiliated with one university. As the perceptions of supported appeared to depend on the method of providing research support, replications of this study that utilize the same intervention method are needed in order to generalize these findings. Although this research is the first to survey needs of clinical nurses across the 10 processes of research, the field would benefit from a comparison of these results on the 10 research processes with data that are collected at other universities.

\section{Conclusion}

Our results indicate that the following factors should be addressed to better support research by clinical nurses: teaching methods, reviewing the literature, selecting the appropriate research method, and analyzing the data. These findings help with the identification of areas of research support that clinical nurses still need. Our results also demonstrated that nurses were dissatisfied with the methods of communication used. Therefore, to promote clinical research through the provision of research support from university faculty, improving communication methods between the university and hospital is needed. To better address nurses 'needs for research support from the university, it is necessary to consider clinical human resource development to support nursing research at institutions. This study's findings have contributed to the improvement of clinical care by effectively identifying areas for future research support in continuing education.

\section{ACKNOWLEDGEMENTS}

We thank all the participants of this research. This work was supported by KANAeru Fund of Sapporo City University.

\section{CONFLICTS OF INTEREST Disclosure}

The authors declare that there is no conflict of interest.

\section{REFERENCES}

[1] Hutchinson M, Johnston L. Bridging the divide: a survey of nurses' opinions regarding barriers to, and facilitators of, research utilization in the practice setting. Journal of Clinical Nursing. 2004 Mar; 13: 304-315. PMid:15009333 https : //doi .org/10.1046/j.13 65-2702.2003.00865.x

[2] Higashino T, Ishigro C, Ono A, et al. Development of research support programs for nurses to continue working in small and mediumsized hospitals Collaboration with hospitals and university. The Japanese Red Cross Medical Journal. 2016; 67(2): 309-314.

[3] Miyashiba T, Nishihira R, Sakashita R. Present conditions and issues of supporting nursing research at the hospitals in Hyogo: an investigation of support system for the research by nurses. University of Hyogo College of Nursing Art and Science \& Research Institute of Nursing Care for People and Community Bulletin. 2010; 17 : 117-129.

[4] Sakashita R, Kitajima Y, Nishihira R, et al. A nation-wide survey of nursing research conducted in medium and large hospitals in Japan. Journal of Japan Academy of Nursing Science. 2013 Jan; 33(1): 91-97. https://doi.org/10.5630/jans.33.1_91

[5] Yokoi K, Nishikawa M, Matumono Y, et al. An attempt to cultivate support for clinical nursing research performed in collaboration be- tween a university and the community -Evaluation of training for improving skills in supporting clinical nursing research. Journal of Human Nursing Studies. 2008; 6: 63-70.

[6] Berelson B. Inaba M. Content analysis. Tokyo: Misuzu Shobou; 1957.

[7] Aoto S, Fujie K, Nakata Y, et al. Clinical Research Support in Mito Kyodo General Hospital: Current Practice and Future Problems. Journal of the Japanese Association of Rural Medicine. 2017; 65(6): 1177-1187. https://doi.org/10.2185/jjrm65.1177

[8] Boland G, Kamikawa C, Inouye J, et al. Partnership to build research capacity. Nursing Economics. 2010 Sep-Oct; 28(5): 314-321.

[9] Latimier R, Kimbell J. Nursing research fellowship: building nursing research infrastructure in a hospital. The Journal of Nursing Administration. 2010 Feb; 40(2): 92-98. PMid:20124962 https : //doi.org/10.1097/NNA.0b013e3181cb9f9e

[10] Lee G, Metcalf S. Building research capacity: Through a hospitalbased clinical school of nursing. Nurse Education Today. 2009 Apr; 29(3): 350-356. Mid:19038479 https://doi.org/10.1016/j. nedt. 2008.10.004

[11] Ohmura Y, Fujino Y, Kawamoto R, et al. Support for nursing research at university hospitals. International Nursing Care Research. 2014; 13(3): 49-59. 